\title{
DE LA PENURIA Y EL LUJO EN LA NUEVA ESPAÑA. SIGLOS XVI-XVIII
}

POR

\section{PILAR GONZALBO AIZPURU}

Centro de Estudios Históricos. El Colegio de México México

Asi como fue proverbial el lujo de los criollos americanos, también llamó la atención de los funcionarios públicos y de los viajeros de otras latitudes el marcado contraste entre la pobreza extrema de algunos grupos y el alarde de riqueza de otros.

Tales contrastes, que en buena medida se han perpetuado en nuestras sociedades iberoamericanas, responden a cuestiones más complejas que la frivolidad ocasional de individuos afortunados. En este texto se indaga acerca del fundamento real del desmedido afán de ostentación de los criollos y de su relación con las posibilidades reales a su alcance.

\section{INTRODUCCIÓN}

"Vanidad de vanidades y todo vanidad, sino amar y servir solamente a Dios.»

Tomás de Kempis, Imitación de Cristo.

Desde la remota antigüedad, poetas y moralistas, políticos y pedagogos, han hablado a favor o en contra de la riqueza y de

SIGLAS UTILIZADAS:

AGNM: Archivo General de la Nación, México.

AHNCM: Archivo Histórico de Notarías, Ciudad de México. 
sus símbolos, y así han contribuido a mitificar el valor de la ostentación, el prestigio de las alhajas y la trascendencia moral y social del vestuario suntuoso y del despilfarro como sucedáneo de la nobleza. El valor relativo de los objetos de uso cotidiano ha propiciado cambios de actitudes hacia la exhibición de la riqueza, a la vez que las fluctuaciones económicas han recomendado el fomento o el freno de la producción de artículos suntuarios.

El boato cortesano, digno de elogio mientras fue exclusivo de los reyes y de los nobles, se convirtió en motivo de escándalo cuando llegó al vestuario y a los salones de comerciantes o artesanos enriquecidos. Por otra parte, lo que en un tiempo se consideraba superfluo y desmedido, pasaría años más tarde a ser de uso común y aún de primera necesidad. El hecho es que, entre alardes de grandeza imperial y exageraciones de ascetismo, la compleja realidad del lujo y de su contrario, la pobreza, expresan a lo largo de la historia la evolución de los símbolos y de los valores tanto como los cambios en la vida material.

La Nueva España fue a lo largo de tres siglos espacio de convivencia forzosa y de ocasionales enfrentamientos de distintos grupos étnicos, de individuos de distintos niveles socioeconómicos y de concepciones vitales dispares y aún antagónicas. El patrón uniformador de la moral cristiana y de la educación humanista penetró hasta cierto punto en las conciencias e impuso modelos universales de conductas y creencias, pero sin dejar de mantener la convicción de la diversidad de gentes y culturas, que invariablemente tendía a aplicar categorías valorativas.

Los dogmas religiosos y las virtudes ensalzadas por el discurso piadoso eran idénticos para todos los novohispanos, pero nadie esperaba que su cumplimiento implicase similares obligaciones para los poderosos y para los desposeídos, para los cristianos viejos y los neófitos, para los propietarios y para sus esclavos y servidores. El orden colonial no dejaba espacio para pretensiones igualitarias; los señores debían identificarse inequívocamente como tales y los indios y gente de color tendrían que mostrar, sin ambigüedades, su condición de vasallos sumisos. De ahí que el lujo, la ostentación y la opulencia fueran una necesidad social y no simple vanidad ocasional de individuos aislados. 
En la sociedad barroca, el parecer noble, honrado, rico y poderoso, era casi tan importante como serlo en realidad. Era lógico, pues, que hombres y mujeres dedicasen sus mejores esfuerzos a engalanar sus casas y personas, de modo que pudieran exhibir cuanto las identificaciones como pertenecientes al grupo privilegiado; los signos externos de distinción adornaban sus viviendas, sus vehículos y sus personas. Precisamente la preocupación exacerbada por el cultivo de las apariencias dio motivo a los escritores de la época para lanzar severas críticas y para reflexionar sobre la futilidad de los bienes terrenos y el loco girar de la rueda de la fortuna, que de momento elevaba a alguien hasta la cumbre para hacerlo descender al día siguiente.

El jesuita Baltasar Gracián, entre filósofo y pedagogo, fijaba su atención en aquellas mudanzas que iban alternando «Las ganancias y las pérdidas, las dichas y las desdichas». Lamentaba los vertiginosos cambios de su tiempo y añoraba la época de los antiguos reyes y conquistadores "pobres de gala y ricos de fama» así como de las mujeres modestas y hacendosas, en cuyo lugar se encontraban ahora damas "con costosos abanicos de varillas de diamantes, fuelle de su vanidad» (1).

Repetidamente se ocuparon los monarcas españoles de dictar ordenanzas y disposiciones reguladoras del lujo (2), al mismo tiempo que, a ambos lados del océano, se escuchaban amonestaciones ascéticas que recomendaban la renuncia a los bienes materiales y el desprecio de toda vanidad. Tomás de Kempis, tan leído y comentado en meditaciones piadosas, advertía de los peligros de la vanagloria, que basaba su satisfacción en el goce de efímeros bienes materiales y de inmerecidas honras y dignidades:

Suma sabiduría es, por el desprecio del mundo, ir a los reinos celestiales. Y pues así es, vanidad es buscar riquezas perecederas y esperar en ellas. Vanidad en buscar lo que tan presto se pasa y no buscar con solicitud el gozo perdurable.

No codicies lo que no te conviene tener. Ni quieras tener

(1) Baltasar Gracián, El Criticón, edición de Julio Cejador, Madrid, Ed. Renacimiento, 1924, pág. 297.

(2) J. Sempere y GuARINos, Historia del lujo y de las leyes suntuarias en España, Madrid, 1788. 
lo que te pueda impedir y quitar la libertad interior. Y así, no cualquier cosa alcanzada o multiplicada exteriormente aprovecha, sino más bien la despreciada y desarraigada del corazón. No entiendas esto sólamente de las posesiones de las riquezas, sino también de la ambición de la honra y deseos de vanas alabanzas, todo lo cual pasa con el mundo (3).

La actitud de las autoridades locales, en este terreno como en tantos otros, fue tan ambigua como lo permitía la obediencia a la metrópoli y tan tolerante como lo exigían las circunstancias. Podía pregonarse en España la nobleza del espíritu y la austeridad del vestido, en donde los rancios títulos de hidalguía eran conocidos y respetados por todos, pero la discutible aristocracia de los más prominentes representantes de la élite criolla requería de elementos de sustentación, que hicieran ostensible la diferencia de calidad de quienes alardeaban de superioridad. Destacar las distancias entre los grupos sociales parecía imprescindible para mantener el orden.

La doctrina de la Iglesia, inflexible en las plumas de fray Alonso de la Veracruz y de fray Bartolomé de Las Casas, se tornó acomodaticia en los sermones y confesionarios de los clérigos regulares y seculares. Poco preocuparon al prolífico dominico y al reflexivo agustino la defensa de privilegios y el afianzamiento del orden autoritario y jerárquico, que violentaba principios elementales de justicia. Ambos consideraron que el único camino para obtener el perdón por las riquezas mal habidas era su restitución. Advertía Las Casas a los confesores de conquistadores y encomenderos, que aún a aquellos cuyos bienes procedieran de "granjerías» y no exclusivamente de rapiña o tributo, les exigieran la devolución de lo superfluo:

Lo primero tásele el gasto ordinario del comer y beber, y vestir suyo y de su mujer e hijos, que sea sólo lo necesario y no más... y modérele toda su casa y el dote de sus hijas, conforme a la calidad de su persona; si fuere baja y lo mismo si fuere de generoso linaje, le ponga en estado muy moderado porque no es lícito de lo ajeno vivir muy pomposamente y

(3) Tomás de Kempis, Imitación de Cristo, México, Porrúa, 1964, págs. 3 y 106.

R. I., 1996, n. 206 
en estado alto, con sudor de hombres prójimos que nada le deben (4).

Fray Alonso, más moderadamente, exigía algo semejante a los responsables de tantos expolios, y extendía la obligación de restituir a sus mujeres, quienes:

sin saber lo que tienen sus maridos ni lo que deven, que cessen de la pompa y vanidad que sustentan y que pongan las joyas y vestidos que tienen superfluos en manos de sus maridos, para que hagan de ellos lo que quisieren, y si de ellos no lo admitieren, podrán ellas ayudar a descargar sus conciencias (5).

Pocos confesores debieron prestar atención a estos consejos, que de todos modos nos advierten sobre un punto esencial en la valoración del lujo: la idea de lo superíluo y de lo necesario y, relacionada con ellas, la de lo adecuado a determinada posición y linaje. Entre la pobreza evangélica y el lujo culpable, quedaba el amplio y sinuoso margen de lo decoroso, que debía hacer compatible la dignidad de una posición social respetable con la modestia y la humildad cristiana.

\section{DE LA POBREZA MERITORIA A LA CODICIA VICIOSA}

iOh qué agradable espectáculo es para los Angeles contemplar abierta la mano del Poderoso para dar, y estendida también la mano del menesteroso para recibir! (6).

En el catecismo de la doctrina cristiana, la primera de las bienaventuranzas se refiere a los pobres de espíritu, aquellos

(4) Bartolomé de LAS CASAS, "Avisos y reglas para los confesores», en Doctrina, México, UNAM, 1972, págs. 135-154, pág. 145.

(5) Ernest J. Burrus, The Writings of Alonso de la Veracruz. The original texts with English Traslation, Jesuit Historical Institute, Saint Louis Missouri University, 1967, pág. 137.

(6) Francisco Javier LAzCano, Exemplo que según la costumbre de los sábados de quaresma predicó en el colegio Máximo de San Pedro y San Pablo, el 27 de marzo de 1756, México, Imprenta de la Biblioteca Mexicana, 1756, pág. 5. 
que "ya no quieren honras ni riquezas, ni aún moderadas», a quienes se promete el reino de los cielos (7). Para el criterio de los creyentes, esta transacción era más generosa que equitativa: renunciar a las satisfacciones limitadas y efímeras a cambio de la eterna e inconmesurable bienaventuranza. Alentados por esta esperanza, muchos jóvenes nobles y acaudalados eligieron el camino del menosprecio de los bienes terrenos e ingresaron en las órdenes regulares, medicantes o no. Pero no sólo dentro de las reglas monásticas y conventuales se podía ejercitar la pobreza como virtud. En la vida seglar, incluso dentro del matrimonio y aún en el desempeño de funciones burocráticas de administración o gobierno, o en empresas productivas, mercantiles, mineras o agrícolas, cabía encontrar el justo medio en la voluntaria moderación de la satisfacción de los apetitos y en el ejercicio caritativo de la limosna.

Teológica y socialmente, los pobres eran justificación viva de la riqueza. En oposición a los protestantes, que convertían en obligación el derecho al trabajo de todos los seres humanos, la iglesia romana proclamó la obligatoriedad de la limosna. El ordenamiento de Carlos I para reglamentar la mendicidad en 1540 provocó la respuesta de Domingo de Soto que, en Deliberación sobre la causa de los pobres, defendió el derecho individual a la libre elección de la pobreza. Para que el reparto de bienes fuera meritorio tenía que ser voluntario, de modo que la responsabilidad de la atención de los pobres no debería convertirse en cuestión burocrática de los municipios, sino en cargo de conciencia de los acaudalados. Juan Luis Vives llegó a considerar ladrón a quien guardaba lo que le sobraba después de cubrir sus necesidades (8). La limosna quedó así como instrumento universal para el ejercicio de la caridad.

En elogio de la limosna se pudo encontrar aplicación práctica a la muy confusa y discutible parábola evangélica del administrador infiel. Según un jesuita novohispano:

assi vosotros, con las riquezas que a otros sirven a la iniquidad y a la culpa grengeeis amigos que os reciban en el Cielo

(7) Jerónimo RIPALDA, Doctrina Christiana con una exposición breve, Burgos, Philippe de Iunta, 1951, pág. 39, y cientos de ediciones posteriores.

(8) Angel LoSADA, "Juan Luis Vives: teoría y proyección sobre la libertad", en Carlos Herrejón Peredo, editor, Humanismo y ciencia en la formación de México, Zamora, El Colegio de Michoacán, 1984, págs. 83-111, págs. 99-101.

R. I., 1996, n. ${ }^{\circ} 206$ 
quando murais (...) el fin para que propuso Christo Nuestro Señor esta parábola no fue otro que para exhortar a los fieles a la misericordia, a la piedad y limosna para con los pobres (9).

La fuerza persuasiva del discurso aumentaba con la oferta de compensación en la vida terrena, independientemente de los méritos sobrenaturales acumulados para la eterna.

... el practicar la misericordia con nuestros próximos y hazer limosnas a los pobres es el medio más cierto e infalible para aumentar copiosamente los caudales, para conseguir riquezas y aun para dexar abundantes y copiosas herencias a los hijos... sabed, pues, que la misericordia para con los pobres es igualmente útil y provechosa para alcanzar los bienes terrenos y celestiales y es útil no menos para la vida temporal que para la eterna (...) porque si bien se atiende, lo que se da a el pobre no es rigurosamente donación sino un mutuo o préstamo santa y excesivamente usuario, porque lo que da el limosnero a el pobre, paga Dios con excesivo y multiplicado logro (10).

Era fácil para los predicadores novohispanos identificar a los indios con los pobres, pero según el armónico modelo aristotélico, las mismas normas tenían que regir para todos, cualquiera que fuera su lugar. Parecería una burla recomendar a los indígenas mesoamericanos que no hiciesen ostentación de unas riquezas que jamás conocerían; para ellos las obras de misericordia podían interpretarse en forma diferente, de modo que siempre el vestido, por exceso o por carencia, tenía una función más simbólica que práctica y una connotación moral que lo relacionaba con el sexto mandamiento (11). El catecismo de fray Pedro de Córdoba, traducido al náhuatl por los dominicos mexicanos, explicaba así el consejo evangélico de vestir al desnudo: "y mucho más a vosotros mismos, porque habeís de haber muy gran vergüenza de haver descubiertas las carnes y

(9) Nicolás Segura, Sermones varios domésticos y panegyricos, México, Imprenta Real del Superior Gobierno, de doña María de Rivera, 1742, pág. 3.

(10) Ibidem, págs. 5-9.

(11) Sobre el simbolismo del vestido y las relaciones pobreza-honestidad he tratado en "Vestir al desnudo», 1993, págs. 329-350. 
mucho más las partes vergonzosas, detrás y delante. Y mirad que es la voluntad de Dios que andeís vestidos y cobijadas vuestras carnes» (12).

Dentro del orden providencial, la existencia de los pobres no sólo era inobjetable, sino imprescindible, ya que a través de la limosna se lograba la manifestación de magnificencia material y de elevación espiritual (13). Los pobres eran el primer lujo de las ciudades barrocas, y la de México los tenía en abundancia. Un prodigio relatado por el padre Eusebio Nieremberg se refería a la forma en que un gran pecador, en la capital de la Nueva España, fue defendido misteriosamente en un trance mortal por un poderoso brazo, en el que apreció la manga de un jubón que había dado de limosna a un pobre, "a lo qual atribuía haverle librado Dios de morir en pecado» (14).

En este, como en muchos otros ejemplos piadosos, la caridad se identificaba con la limosna y ésta con la donación de prendas de vestir. Del mismo modo, el lujo y la vanidad se reflejaban primordialmente en el atuendo personal, aunque ocasionalmente también se proyectara en el ajuar doméstico (15). Sin duda es explicable que de las catorce obras de misericordia fueran las siete "corporales" las que con mayor insistencia se recomendaban, ya que las llamadas espirituales se referían a situaciones difíciles de definir y a obligaciones bastante ambiguas e impopulares, como el dar consejo a quien lo necesitase o perdonar las injurias.

El socorro de necesidades materiales tampoco dejaba mucho margen al ejercicio de la caridad en otros terrenos. Mucho tiempo hacía que el entierro de los muertos no era responsabi-

(12) Pedro de Cóndoba,. Doctrina christiana, para la instrucción y información de los yndios por manera de historia, Ciudad Trujillo, Ed. Montalvo, 1945, pág. 109.

(13) Pilar Gonzalbo Aizpuru, La educación popular de los jesuitas, México, Universidad Iberoamericana, 1989, págs. 162-164.

(14) Juan Eusebio Nieremberg, Práctica del Catecismo Romano y Doctrina Christiana, Madrid, Melchor Sánchez, 1673, pág. 363.

(15) José Durand, "El lujo indiano», en Historia Mexicana, 21, vol. VI: 1, julio-septiembre 1956, págs. 59-74. Es importante el punto de vista de Maravall acerca de la vivienda: José Antonio MARAVALL, "La estimación de la casa propia en el Renacimiento", en Estudios de Historia del pensamiento español, 2 vols., Madrid, Ediciones del Instituto de Cooperación Iberoamericana, 1984, vol. II, págs. 317-330.

\section{R. I., 1996, n.o 206}


lidad individual de los fieles y que la visita de los enfermos se había institucionalizado a través de cofradías y congregaciones. No era fácil encontrar peregrinos necesitados de hospedaje en la Nueva España y tampoco se pensó en que la esclavitud era un cautiverio que debería ser redimido, puesto que las autoridades civiles lo aprobaban y estimulaban. La limosna debía considerar también la donación de comida y bebida, pero ambas cosas eran relativamente baratas, al alcance de las más modestas fortunas y, por tanto no servían como indicadores de la diferente categoría en la escala social. Vestir al desnudo era la recomendación que estaba al alcance de casi todos y que remediaría una carencia ostensible en quienes "afeaban" el panorama urbano, como en los que sufrían las inclemencias del tiempo en las zonas rurales.

En fin, ya que la limosna era un medio de salvación, la riqueza no podría ser condenable; y ya que Dios había querido establecer un orden jerárquico, también debía de ser su voluntad que éste se manifestase externamente. La virtud de la pobreza de los seglares era "no adquirir ni tener algo contra conciencia, y dar de limosna lo que sobra" (16). Los riesgos de la riqueza se debían a que "la ostentación excitaba y enardecía el amor de sí mismo, y la pasión de poseer desenseñaba la virtud y empujaba a cualquier torpeza y deshonra» (17).

Al menos desde el siglo xvi se inició la publicación de críticas en contra del lujo excesivo; y también a partir de la misma época se impuso la necesidad de definir lo que era excesivo, y por tanto pecaminoso. La explicación teológica del primer mandamiento advertía que era grave falta poner la confianza en «las criaturas y en los favores y valías del mundo». Era, además pecado de soberbia enorgullecerse por "cosas vanas o indignas de gloria, como la hermosura del rostro, gentileza de cuerpo, atavíos de la persona, acompañamiento de criados, riquezas, linaje, $u$ otras cosas semejantes, que son de poca sustancia» (18). Y cuando el orgullo se manifestaba en despilfa-

(16) Pedro SÁnchez, Del Reyno de Dios y del camino por donde se alcanza, Madrid, Juan Vázquez del Mármol, 1599, pág. 270.

(17) Desiderio ERASMo DE RotTERDAM, Ensayos escogidos, selección y prólogo de Humberto Martínez, México, SEP, 1984, pág. 257.

(18) Fray LuIS DE GRANADA, "Memorial de la vida cristiana", en Obras, Madrid, Biblioteca de Autores Españoles, tomo 8, Imprenta Rivadeneyra, 1851, págs. 230 y 232 . 
rro de las riquezas, el confesor debería corregir la prodigalidad que, aunque pareciera contradictorio, se relacionaba con la avaricia (19). En el término medio se encontraba la virtud, que sin duda era la de la prudencia, reguladora de los alardes de ostentación y del afán inmoderado de atesorar las riquezas.

La honra del noble exigía que fuera "generoso y liberal», que atendiera las necesidades de su familia y servidores, que fuera "socorro de desvalidos y amparo de virtuosos"; pero existía el riesgo de que se excediera en gastos y lujos, en busca de una gloria parente que lo llevaría a la ruina. Por eso le advertían:

no sólo perderá la honra y estimación verdadera, sino la falsa también; porque tras los vicios anda la pérdida de la hazienda, las trampas y los enredos, la desestimación de sus mismos criados y familiares... y el que avía de ser el socorro de los otros vive público mendigo, rogando a todos que lo socorran, haziendo sobre esto repetidas indecencias. Con que el que havía de ser un Señor rico, honrado, respetado y venerado, viene a ser un poderoso muy pobre, deshonrado, infamado y ultrajado (20).

En las ciudades del México colonial, las casas, las alhajas, el vestuario, los coches y todo lo que se relacionaba con el tren de vida, estaba "medido, decretado y graduado según el rango y las funciones de cada quien" (21). La camisa blanca de los recién bautizados y las capas de terciopelo sobre los hombros de los caciques, los abalorios en el vestido de las damas y los vivos colores en las faldas de las mulatas, el encaje negro en los trajes de iglesia y las finas camisas de Holanda en el ajuar de las novias, todo ello tenía un significado preciso y respondía a una coyuntura en la que calidades, diseños, forma y procedencia de los tejidos y prendas de vestir dependían de circunstancias sociales tanto como económicas.

(19) «Si gasta más de lo que tiene, por lo cual viene a ponerse en necesidad, y faltar en las obligaciones de su casa, y no proveer a sus criados y hijas, o a meterlas monjas por fuerza». Fray LuIS DE GRANADA, Idem., pág. 233.

(20) Juan Palafox y Mendoza, Manual de estados y profesiones. De la naturaleza del indio, México, UNAM, 1986, pág. 35.

(21) Thomas CAlvo, Poder, religión y sociedad en la Guadalajara del siglo XVII, México, CEMCA-H Ayuntamiento de Guadalajara, 1992, pág. 275.

\section{R. I., 1996, n.॰ 206}


El contraste con las zonas rurales era aún más acusado que en Castilla, donde también se apreciaba la gran diferencia entre la austeridad campesina y la ostentación cortesana (22). La mayor parte de la población indígena residía en pequeñas comunidades rurales, donde casi no existían objetos que pudieran identificarse como signos de riqueza, incluso en las casas de propietarios medianamente acomodados. El obispo don Juan de Palafox, en su elogio de las virtudes de los indios, señalaba que aún los caciques y principales, que tenían propiedades y servidores, se conformaban con una modesta vestimenta a la que sólo añadían en ocasiones sombreros y zapatos. (23).

En el extremo opuesto, los plebeyos enriquecidos, cualquiera que fuera su origen, aspiraban a semejarse a los aristócratas y para ello imitaban su forma de vestir. Que el hábito no hace al monje es sólo una verdad a medias, un intento de salvaguardar el precioso orden social. A los ojos de los privilegiados y de los conservadores de la tradición, era inadmisible que cualquiera pudiera vestir como se le antojara (24). En el fondo todos creían que el cambio de ropa propiciaba un cambio de personalidad: la timidez se trocaba en osadía, la sumisión en rebeldía y la humildad en orgullo. En el mundo literario podríamos recordar el reiterado recurso del disfraz varonil que adoptaban las heroínas de las comedias del siglo de oro cuando circunstancias desgraciadas las obligaban a perder el recato y salir en defensa de su honor o de su felicidad (25).

(22) Bartolomé Bennassar, Valladolid en el siglo de oro, Valladolid, Ayuntamiento de Valladolid, 1989, págs. 420-429. También el mismo en Historia de los españoles, 2 vols., Barcelona, Crítica, 1989, pássim.

(23) Palafox, [20], 1986, pág. 73.

(24) Según la apreciación de Roche, los alarmados conservadores consideraban que si no podían fiarse de las apariencias es que el mundo andaba muy mal. Daniel Roche, La culture des apparences, París, Fayard, 1989, pássim.

(25) Y más recientemente, nuestro pulcro y discreto novelista don Juan VALERA, centró el argumento de su novela Juanita La Larga en el escándalo provocado porque una muchacha pobre se atrevió a usar un lujoso vestido de seda. 


\section{ENTRE LA EXALTACIÓN Y LA REPRESIÓN}

... e los sabios antiguos establecieron que los Reyes vistiessen paños de seda con oro e con piedras preciosas por que los homes los puedan conoscer luego que los viessen.

Alfonso X El Sabio, Las Siete Partidas (26).

La grandeza del imperio tenía su espejo en la suntuosidad de las ciudades y éstas se engalanaban con templos y conventos, edificios públicos y amplios espacios para el tránsito de gente, vehículos y mercancías (27). Por su parte, las personas que daban vida al paisaje urbano, le prestaban el toque de elegancia o de miseria correspondiente a su atavío. Según sus entusiastas cronistas, "adorno, utilidad, gracia y belleza» contribuían a la grandeza de la capital de la Nueva España, en la cual podían encontrarse:

galas, libreas, broches, camafeos, jaeces, telas, sedas y brocados, pinte el antojo, pidan sus deseos.

Escarches, bordaduras, entorchados, joyas, joyeros, perlas, pedrería, aljófar, oro, plata, recamados; (28).

Las fiestas religiosas y profanas daban oportunidad para extremar el lujo, ya fuera en el adorno de los altares, en las colgaduras de las fachadas de las casas, en las libreas de los participantes en mascaradas, en los ornamentos de los minis-

(26) Citado por Diego SaAvedra Fajardo, y Pedro Fernandez de NavarreTE, Obras, Madrid, Biblioteca de Autores Españoles, vol. 25, Imprenta de Rivadeneyra, 1853, pág. 519.

(27) Del siglo XVI al XVIII, los viajeros que describieron la opulencia de la ciudad de México se refirieron a sus conventos y edificios de gobierno y de beneficiencia. Ajofrín, Vetancourt y Viera pueden servir de ejemplo. Francisco de Ajofrin, Diario del viaje que, por orden de la Sagrada Congregación de Propaganda Fide, hizo a la América septentrional en el siglo XVIII, México, Instituto Cultural Hispanomexicano, 1964; Agustín de VeTANCourT, Teatro mexicano. Descripción breve de los sucesos ejemplares históricos y religiosos del Nuevo Mundo de las Indias. Crónica de la provincia del Santo Evangelio de México, México, Porrúa, 1971; Juan de VIERA, Breve y compediosa narración de la ciudad de México, México, la edición facsimilar del manuscrito original de 1777, Instituto J.M.L. Mora, 1992.

(28) Bernardo de Balbuena, Grandeza Mexicana, México, UnAM, 1979, pág. 41 .

R. I., 1996, n. 206 
tros religiosos, en las joyas de las damas, en los carros alegóricos o los arreos en los caballos y carrozas. Si la silla de montar de un virrey podía describirse como "promontorio de plata" (29), algo semejante podría decirse de las vajillas y floreros que se exhibían en las vitrinas de los salones o sobre las mesas de los banquetes.

El cabildo de la ciudad, celoso vigilante de su prestigio como corporación, cuidaba con particular esmero la preparación de las fiestas y al atuendo que llevarían sus miembros en procesiones, funerales y paseos; los gastos en prendas de luto o en galas festivas se cargaban a las rentas de la ciudad y se consideraban una inversión provechosa, que se recuperaba en forma de respeto popular y consolidación del poder (30). Los relatos de festejos en la capital no dejaron de referirse al costoso vestuario de señores y pajes durante diversas celebraciones (31). Como correspondía a lo que representaban, las imágenes de los santos lucían con similar esplendor coronas y alhajas que enriquecían su vestuario (32).

Entre los cambios de mentalidad propiciados por el Renacimiento, fue notable el surgimiento de la moda, con un carácter nacionalista, que diferenciaba la manera de vestir de cada uno de los países europeos, antes tan semejantes entre sí. De este modo, por un tiempo se prestó mayor atención a la invención y conservación de estilos peculiares de determinadas regiones, pero pronto se convertiría en timbre de orgullo para los nobles y potentados el vestir a la moda extranjera, con preferencia francesa (33). En la Nueva España el entrecruzamiento de influencias se complicaba al valorarse el prestigio

(29) En la "relación escrita a una religiosa prima suya», por María de EsTRADA MEDINILla, en Viaje por tierra y más feliz por mar y tierra, citado por Josefina MURIEL, Cultura femenina novohispana, México, UNAM, 1982, págs. 125-135.

(30) Sobre la función de las fiestas en la sociedad novohispana he publicado recientemente un artículo, Pilar GonZalbo, "Las fiestas novohispanas: espectáculo y ejemplo", en la revista Mexican Studies/Estudios Mexicanos, volumen 9: 1, 1993, págs. 19-46.

(31) Antonio de Robles, Diario de sucesos notables, 3 vols., México, Porrúa 1946, vol. I, pág. 72, vol. III, pág. 129 y pássim.

(32) Idem., vol. I, págs. 95, 112, 158, 205, 220 y pássim.

(33) Carmen BERNIS, Indumentaria española en tiempos de Carlos V, Madrid, Consejo Superior de Investigaciones Científicas, 1962, pág. 20. 
de lo tradicional español frente a lo indígena y de lo afrancesado, novedoso sobre lo antiguo. Aunque vestir a la moda no significaba necesariamente utilizar prendas más costosas, así lo interpretaban quienes advertían que los cambios de telas, estilos y colores imponían la renovación frecuente del vestuario. Si en cualquier circunstancia podrían encontrarse justificaciones para el éxito de la moda, en la sociedad colonial sobrarían razones, ya que la relativa uniformidad impuesta por sastres y modistas se compensaba con la riqueza de los accesorios, lo que permitía simultáneamente subrayar la pertenencia a un grupo y la distinción personal (34).

Por contraste con la frivolidad de la moda cortesana, el vestuario de las sociedades rurales y de los pobres, en la Nueva España, como en cualquier latitud, tuvieron una evolución lenta y tardía.

La cultura de las apariencias fue manifestación de un cambio profundo en las costumbres. Una vez superado el nivel del consumo necesario, era fácil encontrar la justificación del ornato ostentoso. Ya en pleno siglo XviII, el debate de las Luces sobre el lujo enfrentó la vieja tradición cristiana con la nueva sensibilidad liberal. En la sociedad estable desigual se admitía el lujo como un medio de que las riquezas de unos cuantos revertieran en el bien común, proporcionando trabajo y ocupación. En la mentalidad ilustrada quedaba establecida la diferencia entre el «lujo de comodidad» y el «lujo de ostentación» (35).

A veces confunde al historiador el encontrar designada con diferentes palabras una misma prenda o, al menos alguna muy similar a otras conocidas; hay que advertir que también esta inestabilidad de los vocablos contribuía a afianzar la idea de lo cambiante. Por otra parte, aunque a través de los siglos siguieran usándose faldas, sayas, camisas y corpiños, calzas, jubones y sayos, capas, capotes, mantones y mantillas, lo que distinguía a los elegantes era la mutación en las cortes, texturas y colores de las telas, las combinaciones de brillos, brocados, adornos,

(34) Barthes ha señalado la forma en que observaciones concretas sobre características de una prenda se convierten en elementos representativos de una forma de vida. Roland BARTHES, Système de la mode, Paris, Editions du Seuil, 1967, pág. 31 .

(35) Roche [24], pág. 507

\section{R. I., 1996, n.o 206}


bordados y joyas, y, sobre todo, la permanente sorpresa de los cambios estacionales.

$\mathrm{Y}$ así como los reyes habían sido los primeros en lucir espléndidas galas, ellos debían remediar los excesos de sus súbditos, puesto que se consideraba que era "obligación del príncipe poner límite y raya a la prodigalidad de sus vasallos», prodigalidad tanto más onerosa cuanto que la compra de joyas y de vestidos llevaba consigo la salida de oro hacia los países extranjeros que las exportaban (36). También el contrabando de telas y prendas de vestir procedentes de la China afectaba a las arcas reales, al evadir el jugoso impuesto con que estaban gravadas, y por ello se repitieron en distintas ocasiones las prohibiciones al libre comercio (37).

Así como se promulgaron disposiciones sobre el lujo y el comercio, otras pretendían extinguir el uso de trajes representativos de viejas tradiciones vistas con recelo. Una denuncia contra los alcaldes indios del barrio de San Juan, en el año 1564, mencionaba que: «en los mitotes que se hacen, se visten y componen de unos trages y devisas que eran costumbre de ponerse e vestirse aquellos viejos antepasados, quando yvan a idolatrar e hazer sacrificio de alguna persona dándole muerte» (38). La desnudez de los indígenas, como vestigio de sus antiguas costumbres, era al mismo tiempo signo de rebeldía y muestra de apatía y pereza; por ello una real cédula que recomendaba la compulsión al trabajo, advertía a los doctrineros que «persuadan a los Yndios que anden vestidos, para más honestidad y decencia de sus personas» (39). Los gitanos se

(36) Fernández de NavarRete [26], pág. 515.

(37) «Los contadores de Lima y México procuren y hagan guardar las prohibiciones sobre la ropa de China y que en los navios que se permiten al trato no passe de Nueva España a Perú", "La ropa de China de contrabando se quite a quienes la transportan", "La ropa que llegue a Nueva España se consuma ahí", "No se pueda comprar, vender ni permutar, aunque se diga que es por vía de donación"; en Recopilación de Leyes de los Reynos de las Yndias, mandadas imprimir y publicar por la Magestad Católica del Rey don Carlos II, 4 vols., edición facsimilar de la de 1681, en Madrid, Cultura Hispánica, 1973, Libro VIII, título I, ley 103, fol. 17; libro IX, título XLV, ley 67, fol. 131, y ley 68; fol. $131 \mathrm{v}$.

(38) Códice Osuna, México, Instituto Indigenista Interamericano, 1947, pág. 14.

(39) Recopilación, Libro VI, título I, Ley 21, fol. 190. 
veían como potencial amenaza de disolución de costumbres, por lo que también fueron objeto de represión: «Han passado y passan algunos gitanos y vagamundos, que usan de su trage, lengua, tratos y desconcertada vida entre los Indios, a los quales engañan fácilmente» (40). Es vien conocida la ley relativa al atuendo de negras y mulatas, a quienes estaban prohibidos los mantos y las joyas y el uso de los trajes propios de las indias (41).

Si bien las restricciones para el uso de la seda y otras telas lujosas existían en Castilla desde tiempo de los Reyes Católicos, habían considerado los monarcas la necesidad de establecer excepciones a favor de determinados funcionarios, a quienes se les autorizó a trasladar sus pertenencias sin limitaciones y con franquicia, cuando iban a servir cargos públicos en las posesiones de Ultramar. Una nueva pragmática contra la ropa suntuosa, promulgada en la Nueva España en 1571, quedó sin efecto tras repetidas solicitudes de prórroga para su aplicación (42).

En las disposiciones reales sobre el vestido existía un claro sentido político de regulación social. Ya en Castilla se había determinado "qué personas pueden traer seda y en qué forma la pueden traer" y los procuradores en Cortes habían detallado minuciosamente las cinco categorías establecidas para diferenciar con claridad a los señores de los plebeyos (43). En la sociedad novohispana, la importancia de la ropa como símbolo cultural, adquiere especial relieve al considerar cómo la Corona española reconocía la igualdad de las almas de todos sus súbditos, pero les imponía la diferenciación en el vestido. Los indios aceptaron tempranamente las prendas impuestas por

(40) Recopilación, Libro VII, Título V, ley 18, fol. $290 \mathrm{v}$.

(41) Recopilación, Libro VII, título V, ley 18, fol. 290 v. También en las Ordenanzas de la Audiencia de México, recopiladas por Ventura Beleña, vol. I, pág. 111.

(42) Acta de Cabildo de 5 de mayo de 1571, en Edmundo O'Gorman, Guia de Actas de Cabildo de México en el siglo XvI, México, Fondo de Cultura Económica, 1970, pág. 73 .

(43) Carmen Bernis, Trajes y modas en la España de los Reyes Católicos, 2 vols. (vol. I: las mujeres; vol. II: Los hombres) Madrid, Consejo Superior de Investigaciones Científicas, 1978-1979, vol. II, págs. 57-60.

R. I., 1996, n.० 206 
los conquistadores (44), los negros y mulatos encontraron medios de conservar su sentido estético sin contravenir las normas, (45) y los españoles compitieron por demostrar su distinción por medio del vestido.

La preocupación por la deshonestidad en el vestir fue obsesión de los religiosos, que solicitaron la intervención del Consejo de Indias con el fin de moderar lo que consideraban excesos de los fieles y que incluía el atrevimiento de algunas mujeres y la «indistinción con que igualmente visten sedas y telas preciosas y usan joyas de oro y plata los nobles y plebeyos» (46). Hablar de un vestido y un porte modestos significaba igualmente definir discreta pobreza y virtud. Los numerosos bandos publicados contra la desnudez de léperos y mendigos, ya en el siglo xvIII, manifestaban la inquietud ante la posible rebeldía de los marginados (47).

Los prelados ilustrados Alonso Núñez de Haro y Peralta, arzobispo de México y Francisco Fabián y Fuero, obispo de Puebla, mostraron especial preocupación por el atuendo de sus feligreses, que ofendían a Dios con su atrevimiento, ya por el descoco de las mujeres o por la irrelevancia de los participantes en celebraciones religiosas (48). La asimilación de las normas lega-

(44) Las Relaciones geográficas, dan claro testimonio de esta rápida adopción de pantalones de algodón por parte de los hombres y faldas y camisas por las mujeres.

(45) La popular cita de Thomas Gage no sólo se refiere al garbo y sensualidad de las mulatas, sino también a la vistosidad de su vestimenta. Thomas GAGE, Nuevo reconocimiento de las Indias Occidentales, México, SEP ochentas, 1982, pág. 188 .

(46) Real Cédula al Virrey de la Nueva España, para que atienda a que en lo posible se remedien las deshonestidades y trajes inmodestos que se usan en México. Dada en el Buen Retiro, a 29 de diciembre de 1679; en Richard KONETZKE, Colección de documentos para la historia de la formación social de Hispanoamérica, 1493-1810, Madrid, Consejo Superior de Investigaciones Científicas, 1951-1953, vol. III, pág. 693.

(47) Norman MARTIN, «Pobres, mendigos y vagabundos en la Nueva España, 1702-1766", en Estudios de Historia Novohispana, vol. VIII, 1985, pág. 261. También Norman MARTin, Los vagabundos en la Nueva España. Siglo XVI, México, Jus, 1957, pássim.

(48) Francisco FABIÁN y FUERo, Colección de providencias diocesanas del obispado de Puebla de los Angeles, Puebla, Imprenta del Real Seminario Palafoxiano, 1770, pág. 121, «en que se prohíbe gravemente el que todas las mujeres de cualquier estado y calidad vayan tan escotadas que descubran 
les y morales impulsaba a algunas mujeres a no salir de su casa, ni aún para asistir a la iglesia, cuando no disponían de ropa decorosa con la que presentarse en público (49).

\section{El LUJO de los NOVOHISPANOS}

son tantos y tan excesivos los trajes en esta tierra, de lo qual redunda grandes ofensas a Dios Nuestro Señor y molestias y vexaciones de los pobres naturales (50).

El lujo y la moda parecen ser privativos de determinados grupos sociales; sólo que lo que se aprecia como lujo en algunos individuos puede ser simplemente comodidad necesaria en otros. También sucede que los elementos de ornato adecuados a cierta situación de opulencia sirven para fingir apariencias de prosperidad en circunstancias menos favorables. La euforia de la riqueza fácil embriagó a muchos de los conquistadores, que de inmediato se sintieron con derecho a ostentar escudos y blasones, a la vez que se adornaban con terciopelos y brocados. No fueron pocos los que perdieron sus riquezas antes de que se

el pecho y el que entren en las iglesias con velos transparentes». La cuestión de los velos ya había preocupado al jurista hispano Antonio Rodríguez de León Pinelo, que expuso sus argumentos en el libro Velos en los rostros de las mujeres: sus consecuencias y daños, 2 vols., edición facsimilar de la de 1641, en Madrid, imprenta de Juan Sánchez, en Santiago de Chile, Curiosa Americana, 1966.

Alonso Núñez de Haro y Peralta, Sermones escogidos, pláticas espirituales privadas y dos pastorales, Madrid, Imprenta de la hija de Ibarra, 1806, pág. 283 , sobre las «mujeres que entran en la iglesia coqueteando, adornadas y compuestas para atraer la mirada de los hombres». También sobre lo mismo en: Fortino Hipólito VerA, Colección de documentos eclesiásticos de México, o sea antigua y moderna legislación de la iglesia mexicana, 3 vols., Amecameca, Colegio Católico, 1887, vol. I, págs. 127 y 411.

(49) Salvador de la GANDARA, Carta que sobre la vida y muerte del padre doctor Francisco Xavier Lazcano, dirige a los padres de la Compañia de Jesús de la provincia de México, México, Imprenta del Colegio de San Idelfonso, 1763. pág. 51.

(50) Carta de Fray Angel de Valencia, custodio de la orden de San Francisco y otros religiosos a Su Majestad. Guadalajara, 8 de mayo de 1552; en Cartas de Indias, 5 vols., México, Secretaría de Hacienda y Crédito Público, 1981 , vol. I, pág. 117.

R. I., 1996, n.॰ 206 
ajasen las sedas, y no hubo ninguno que aceptase un descenso de categoría como consecuencia de la pérdida de su fortuna. Orgullosos de sus hazañas bélicas confiaban en que la Corona les concedería mercedes que los librarían de la pobreza y podrían seguir alardeando de las insignias del rango al que creían pertenecer. Con ello consideraban que prestaban un servicio a la monarquía tanto como a sí mismos (51).

Mientras que los religiosos clamaban escandalizados contra el desorbitado derroche de los primeros pobladores españoles, un funcionario corrupto como Nuño Beltrán de Guzmán defendía paladinamente su derecho al despilfarro, que más debería juzgarse como virtud que como falta. Aquéllos reprochaban el atrevimiento de los plebeyos, "oficiales, mecánicos y criados de otros de baja suerte, y mujeres de la misma calidad, y enamoradas y soldados, que andan cargados de sedas, capas y sayos y sayas y mantos, y de esto se sigue mucho daño a la tierra, porque se gastan y destruyen los vecinos y quedan pobres y adeudados» (52). El despótico presidente de la Primera Audiencia alegaba que había sacrificado su propia hacienda en beneficio de la prosperidad de la colonia: "por honrar el lugar que Su Magestad me había dado y por regocijarlos a todos, me puse en necesidad y deudas; en tierra que se comenzaba nuevo mundo y haber ley y orden y quitar la libertad pasada era necessario liberalidad y gastar» (53).

Era inevitable que el costo de la ostentación recayera sobre los indios y ahondara la ya profunda distancia entre la riqueza de unos cuantos españóles y la miseria de casi todos los indígenas (54)., Ante las aspiraciones de grandeza de los artesanos y

(51) Hay numerosos ejemplos de estas actitudes en las solicitudes presentadas por conquistadores y descendientes, en las que resaltan sus méritos, su incapacidad para trabajar en cualquier oficio y su pobreza relativa, dada la posición de prestigio que les corresponde. Francisco ICAZA, Conquistadores y pobladores de Nueva España. Diccionario autobiográfico, sacado de los textos originales, 2 vols., Madrid, Impr. El Adelantado de Segovia, 1923, pássim.

(52) «Memoria de los servicios que había hecho Nuño de Guzmán, desde que fue nombrado gobernador de Pánuco de 1525", párrafo 13; citado por Fausto Marín TAMAYo, Nuño de Guzmán, México, Siglo XXI, 1992, pág. 98.

(53) Ibidem, pág. 99.

(54) «No se cognosce el mayor ni el menor, el zapatero y el cavallero, y como por esta causa anden tan alcanzados los españoles, no tienen otro remedio si no es bolverse a estos pobres indios, de donde se sacan todos sus 
comerciantes, la respuesta de los funcionarios reales y de los más acaudalados propietarios criollos fue aumentar el esplendor de su ajuar doméstico y personal. El primer virrey arribó con un impresionante equipaje en el que se acumulaban las ricas prendas de vestir que usarían sus parientes y servidores; (55) el segundo Marqués del Valle trasladó a la capital del virreinato la pompa cortesana con la que se había familiarizado en Valladolid y Madrid (56). El transcurso del tiempo no disminuyó el gusto de los criollos por la exhibición de sus riquezas, de modo que para fines del siglo xviII era común la opinión de que se gastaba exageradamente en alardes de riqueza. El vizconde de Pages advertía la carestía del vestido, Juan de Viera criticaba que los «gastos extraordinarios y superfluos» e Hipólito de Villarroel proponía que se prohibiera a los vecinos de la ciudad que no acreditasen riqueza o hidalguía el uso de ciertas prendas de ropa.

Durante los años inmediatamente posteriores a la conquista, el consumo de productos españoles era un lujo que satisfacía el deseo de prestigio y las ansias por calmar la nostalgia de sabores, olores y colores de la tierra natal. Con el transcurso del tiempo, se regularizó el abastecimiento de mercancías ultramarinas, sin que por ello desapareciera el atractivo de todo lo que mantuviera el arraigo a la madre patria. De este modo, cualquier prenda de ropa que en Castilla no habría llamado la atención, se convertía en signo de distinción en cuanto atravesaba el Atlántico, lo que de paso la encarecía exageradamente. A sabiendas de que por la ropa española se pagaba mucho más de su valor real, los criollos la adquirían, deseosos de imitar el estilo europeo que veían en los gachupines. Según la opinión de los contemporáneos, la moda europea era común entre la "gente principal» (57).

Al contrastar la supuesta elegancia de esta gente principal con la desnudez de los más pobres, quedarían ausentes de la

faustos». En la carta de Fray Angel de Valencia, 1552, en Cartas de Indias, vol. I, pág. 117 .

(55) José R. Benitez, El traje y el adorno en México, 1500-1900, Guadalajara, Imprenta Universitaria, 1946, pág. 42.

(56) Juan SuÁrez de Peralta, Tratado del descubrimiento de las Indias, nota preliminar de Federico Gómez de Orozco, México, SEP, 1949, págs. 111-114.

(57) AJOFRIN, [27]., pág. 77.

R. I., 1996, n.o 206 
comparación todos los que no pueden incluirse en ninguna de las dos categorías. Estos, que no poseyeron títulos nobiliarios ni grandes propiedades y que tampoco desempeñaron oficios de distinguidos en la administración pública, constituyeron la mayoría de quienes a causa de su menguada fortuna tuvieron que elegir entra la satisfacción de sus necesidades y el mantenimiento de las apariencias de señorío.

La rica información procedente de inventarios, testamentos y cartas de dote, nos permite asomarnos a la vida cotidiana de los novohispanos y valorar con su conocimiento que en ocasiones es más preciso del que tuvieron sus contemporáneos, hasta qué punto se sacrificaba el bienestar en aras de las apariencias y cuáles eran los componentes del ajuar y del vestuario a los que se dedicaba buena parte de la fortuna. Ante las numerosas preguntas que pueden plantearse, contamos con algunas respuestas relativas a los cambios en el vestuario desde el siglo XVI al XVIII, a las diferentes actitudes masculinas y femeninas ante las imposiciones de la moda, y a la proporción entre el caudal disponible y la parte del mismo que se destinaba a objetos de ornato.

Los inventarios elaborados en los casos de fallecimiento de varones que no dejaron testamento, entre 1705 y 1754, proporcionan una imagen bastante clara de la forma en que la situación económica se reflejaba en el atuendo personal y de cómo la profesión y el medio ambiente determinaban las exigencias sociales de presentación. La mayor parte de los bienes registrados corresponde a negocios y propiedades, entre los que predominaron las tiendas y sus mercancías, los inmuebles urbanos, las fincas rústicas, el ganado y los documentos de crédito. Del caudal total considerado, la parte correspondiente a objetos de uso personal y doméstico representa un promedio de 24 por 100. Dentro de este apartado, los muebles, la ropa blanca y accesorios del hogar suman un 55 por 100 , en contraste con el 45 por 100 acumulado en prendas de vestir.

De los 28 casos considerados, sólo en cuatro de ellos el valor de la ropa supera al doble de lo correspondiente al ajuar, en 11 es prácticamente igual y en los restantes es claramente inferior. Dado que el valor de los muebles era insignificante en casi todos los casos, se puede hablar de cierto equilibrio entre los bienes de uso personal y doméstico. De todos modos, el va- 
lor de la ropa masculina era inferior en promedio a la femenina, así como también era menor el número de prendas de vestir que tenían los hombres en relación con las mujeres.

No sería fácil establecer algún tipo de relación entre fortuna y vestuario, ya que los más acaudalados apenas sobrepasaban en algunas decenas de pesos a los más humildes. Un cacique indio de Tepeji de la Seda ofrece el ejemplo extremo, al dejar tan sólo 9 pesos, distribuidos entre ropa personal, con valor de 8 pesos y 1 real, y ajuar doméstico, evaluado en 7 reales. La ropa de un capitán de fragata español, con bienes por 12,075 pesos, se valoró en 95 y la del dueño de una pulpería en Veracruz, con caudal de 1,143, se tasó en 91. Los clérigos disponían de un atuendo que valía como mínimo 29 pesos y como máximo 65; y los comerciantes contaban con prendas hasta por 170 ó 200 pesos. Resulta bastante claro que los habitantes de zonas rurales, aun siendo propietarios de ranchos y ganado, gastaban insignificantes cantidades en la ropa, en comparación con los vecinos de las ciudades y, en particular, con los funcionarios, como el alcalde mayor de Mérida, que dejó trajes por 481 pesos, con lo que alcanzó la cantidad más alta registrada (58).

Las dotes femeninas presentan algunas variantes, pero mantienen la constante de una considerable proporción en dinero (en reales, según la expresión usual) y de una cierta semejanza entre las cantidades destinadas al atuendo personal y las invertidas en mobilario y accesorios del hogar. A partir de un fondo mucho más numeroso que el de los inventarios masculinos, las dotes para matrimonio de los siglos XVI a XVIII dan una idea de los cambios sociales dentro del grupo de origen español. La gran diferencia entre ricas encomenderas y pobres doncellas huérfanas durante el siglo xvi se aprecia en el monto de las dotes, inferiores a los 500 pesos para las que no disfrutaban de encomiendas. A lo largo del siglo xvir se produjo un moderado enriquecimiento general de las familias criollas, que permitió dotar un buen número de jóvenes con cantidades entre 2,000 y 5,000 pesos, mientras eran excepcionales las fortunas superiores a esas cantidades. El siglo XVIII proporciona de nuevo la imagen de grandes diferencias entre las numerosas mujeres dependientes de las dotes de obras pías, que se fijaban en 300 pe-

(58) AGNM, Ramo Intestados, varios volúmenes y expedientes.

R. I., 1996, n.0 206 
sos y las ricas hijas de comerciantes o mineros, que aportaban al matrimonio caudales de más de 10,000 pesos; el grupo de las dotes de 2,000 y 5,000 se hizo proporcionalmente mucho menos numeroso (59).

Una selección de 45 dotes del siglo XVII, superiores a los 500 pesos e inferiores a los 10,000 proporcionan la imagen más aproximada de la distribución de la aportación femenina a los bienes familiares. El porcentaje promedio en dinero resulta ser del 46 por 100 en las dotes inferiores a 1,000 pesos y del 48 por 100 en las superiores, lo que significa una notable semejanza entre personas de muy diferente nivel económico. El mismo cálculo en dotes del siglo xviII muestra el 57 por 100 para las inferiores a 1,000 y 50.5 para las más altas.

Descontadas las aportaciones en bienes inmuebles, urbanos o rústicos, en dinero efectivo, esclavos, mercancías de comercio y documentos, quedaba propiamente el ajuar nupcial, integrado por muebles, ropa blanca, objetos de uso y ornato doméstico, alhajas y ropa personal. En este grupo puede apreciarse la importancia que se concedía a las apariencias, la relación entre la elegancia exterior y la comodidad o austeridad del mobilario y de los utensilios de uso cotidiano. El dormitorio y el estrado eran las habitaciones en que debía transcurrir el tiempo de las amas de casa, y su aderezo les correspondía precisamente a ellas, que llevaban al hogar conyugal la cama, varias sillas o cojines, alfombras más o menos bien conservadas, alguna mesa $\mathrm{y}$, con frecuencia, un biombo o radaestrado (60). A lo largo de los tres siglos de vida colonial hubo cambios en la apreciación de la comodidad hogareña: el dormitorio se tornó más íntimo y el estrado aumentó en importancia, los cojines redujeron su tamaño y precio al pasar de ser asiento único a complemento confortable de sillas y bancas, los arcones dejaron lugar a los armarios, y la plata se exhibió con mayor alarde en aparadores y vitrinas. Pero no hubo sensibles cambios de actitud por parte de las novias y sus parientes, que proporcionalmente siguieron

(59) Pilar GonZALBO, "Las cargas del matrimonio», artículo en prensa en el volumen colectivo Familia y vida privada en la historia de Iberoamérica, coords. Pilar GonZalbo y Cecilia Rabell, edición UNAM-El Colegio de México.

(60) He señalado algunas características de la evolución del mobilario doméstico en mi artículo: "Ajuar doméstico y vida cotidiana", en El arte y la vida cotidiana, UNAM, Instituto de Investigaciones Estéticas, en prensa. 
dedicando la misma atención al arreglo de la vivienda y al adorno de su persona.

Es notable que prácticamente en todas las cartas de dote se mencionen cuadros o grabados, con marcos dorados, tallados o sencillos, y dedicados a advocaciones religiosas en abrumadora mayoría; ocasionalmente se acompañan de algunos paisajes (países) o, más raramente, de escenas de la historia clásica. Su precio es casi siempre superior al de los muebles y su número tan alto que pueden imaginarse paredes virtualmente cubiertas con ellos. También la tapicería que guarnecía las camas era mucho más costosa que el mueble propiamente dicho, aunque contase con cabeceras ricamente decoradas: rodapiés, colgaduras, colchas y tapetes de las mesillas de noche sobrepasaban con creces el costo de la estructura del lecho. Sumados todos los elementos destinados al arreglo de la casa, proporcionan sumas equivalentes a las que corresponden a la ropa de uso personal; y una equivalencia similar se puede establecer entre las alhajas que completaban el adorno de las damas y la plata que relucía en sus salones.

Aunque por regla general las joyas no rompen el equilibrio entre los componentes del caudal, hay ocasiones en las que resulta difícil catalogarlas adecuadamente, ya que hay fuertes indicios de que se consideraban como fortuna más que como adorno personal. En las dotes inferiores a 1,000 pesos, los vestidos costaban mucho más que las alhajas, mientras que por encima de esa cantidad quedaban mucho más que las alhajas, mientras que por encima de esa cantidad quedan casi equilibrados, con 20 por 100 y 18 por 100 del monto total de la dote respectivamente en cada grupo. El joyero de la hija del marqués de Altamira, al casarse con Domingo Trespalacios y Escandón, fue el más suntuoso registrado, con un valor de 12,805 pesos, poco más de la quinta parte de lo que correspondía a la joven como parte legítima de la herencia materna, en la que el valioso ajuar se completaba con 30,000 pesos en reales (61).

En el siglo xVIII, coincidiendo con el aumento de los caudales aportados como dote, hay también una mayor presencia de joyas y metales preciosos. Mercaderes, plateros y oficiales rea-

(61) Capitulaciones matrimoniales y recibo dotal, en 14 de agosto de 1751. Escribano número 743, José Zarazúa; AHNCM, vol. 5227.

R. I., 1996, n. 206 
les, muchos de ellos españoles peninsulares, recibían al desposar a doncellas criollas un suntuoso mobilario, elegantes atuendos y deslumbrantes vajillas de plata que se exhibirían en vitrinas especialmente diseñadas para ello. A diferencia de lo que era habitual entre los hombres, cuyo vestuario no exigía fuertes dispendios ni mostraba grandes diferencias entre los más encopetados y los funcionarios o comerciantes de medianas posibilidades, las mujeres más ricas gastaban mucho más en ropa que las más modestas; aún así, las impresionantes cifras absolutas no llegan a romper notablemente las proporciones relativas entre dinero, ajuar y vestidos.

$\mathrm{Ni}$ entre las desposadas más humildes ni entre las más aristocráticas y acaudaladas podría decirse que el culto a las apariencias les exigiera realizar gastos superiores a sus posibilidades económicas reales. Sin embargo, esta consideración podría no ser tan categórica, si tenemos en cuenta que el lujo no sólo se mide por su precio sino también en relación con las necesidades que pretende satisfacer. Contemplado desde esta perspectiva el conjunto de inventarios de ropa femenina muestra que todas las mujeres que acudían ante el escribano público para acreditar sus pertenencias, poseían al menos un manto, una o más sayas o vestidos y varias camisas y corpiños. El número de estas prendas es proporcional a la disponibilidad de dinero y al adorno del hogar.

Parece desproporcionado, y desde luego es excepcional, que una señora luciera un vestido de 500 pesos, el cual podía alternar con basquiña de raso y ropilla de tafetán por otros 300 , cuando el total de su dote ascendía 2,000 (62). Durante los siglos xVII y $\mathrm{xVIII}$, los vestidos más suntuosos, de brocado y con guarniciones doradas, se cotizaban entre 100, 115 y 130 pesos, mientras que los más sencillos se tasaban entre 25 y 60 . Lo más frecuente era que se mencionaran dos de estos vestidos, además de algún manto o mantellina, sayas, bombachas y enaguas y al menos cuatro o seis camisas. El tapapiés, que al parecer usaban preferentemente las señoras acomodadas, costaba aproximadamente lo mismo que un vestido completo, siempre era de seda, terciopelo o brocado, con bordados, galones y aplicacio-

(62) Carta de dote fechada en 14 de septiembre de 1605, ante el escribano número 555, José Rodríguez; AHNCM, vol. 3836. 
nes y tenía las ventajas de ser más duradero y de adaptarse a cualquier talla, ya que iba sobrepuesto a la falda y la saya. En una época en que la ropa se heredaba a través de varias generaciones, no es raro que las prendas de uso exterior fuesen muy costosas puesto que al cabo de los años quedaría ampliamente amortizado el desembolso inicial. Por las mismas fechas, capas, capotes y casacas eran las prendas más caras del vestido masculino, y podían oscilar entre los 6 y los 24 pesos. Al menos dos de estas prendas aparecieron mencionadas en casi todos los inventarios, mientras que el número de camisas y calzones fue mucho más elevado, entre 3 y 14 (63).

Las frecuentes quejas de los contemporáneos por el lujo inmoderado, podrían responder a la inquietud provocada por el contraste ostensible entre los dueños de tantas alhajas y los desposeídos de todo; pero a la luz de los documentos, no se justifican como protesta por el despilfarro y el alarde de riquezas ficticias. Incluso las gentes de pocas posibilidades económicas se abastecían de ropa de segunda mano en mercados como el Baratillo, al que llegarían algunas prendas robadas pero otras muchas procedentes del guardarropa de damas y caballeros de la corte que desechaban los restos de indumentaria pasada de moda. Progresivamente, a partir de comienzos del siglo XVIII, el auténtico lujo consistió en la renovación del vestuario más que en la ostentación de telas suntuosas; la exhibición de joyas, bordados y adornos fue el lujo accesible a los grupos menos pudientes, pero con aspiraciones de distinción.

Durante los últimos años de vida colonial, la pobreza se encontraba recluida en las celdas de los conventos y el lujo se vivía como rutina cotidiana. Un lujo que, por tanto, no se basaba en ocasionales y extravagantes alardes de ostentación, sino en el compromiso asumido por la sociedad criolla de mantener el lustre de sus apellidos y el prestigio de la vida urbana.

(63) AGNM, Ramo Intestados, varios expedientes.

R. I., 1996, n.o. 206 
Just as the luxurious inclinations of American criollos was proverbial, public officials and travellers from other countries were also structk by the marked contrast between the extreme destitution of some social groups and the ostentation of wealth by others. Such contrasts, which to a large extent have been perpetuated in our Iberian American societies, reflect more complex issues than the occassional frivolity of fortunate individuals. This study questions the real fundaments of the limitees obsession with ostentation of the criollos and its relation to the real choices within their reach. 